Review article

\title{
Takayasu arteritis - epidemiology, pathogenesis, diagnosis and treatment
}

\author{
Dominika Podgórska ${ }^{1 *}$, Rafał Podgórski ${ }^{2,3}$, David Aebisher ${ }^{4}$, Piotr Dąbrowski ${ }^{1}$ \\ ${ }^{1}$ Clinical Provincial Hospital No. 2, Department of Rheumatology, Rzeszów, Poland \\ ${ }^{2}$ University of Rzeszów, Centre for Medical and Natural Sciences Research and Innovation, Rzeszów, Poland \\ ${ }^{3}$ University of Rzeszów, Faculty of Medicine, Department of Biochemistry, Rzeszów, Poland \\ ${ }^{4}$ University of Rzeszów, Faculty of Medicine, Department of Human Immunology, Rzeszów, Poland
}

\section{Abstract}

Takayasu disease belongs to the group of autoimmune vasculitis which most often affects the aorta and its branches. It is rare, and it mainly affects young women. Recent epidemiologic studies suggest that Takayasu arteritis is being increasingly recognized in Europe. The first symptoms are non-specific and an early diagnosis is difficult and requires clinical awareness and suspicion. Patients with Takayasu arteritis often present increased inflammatory markers, including C-reactive protein and erythrocyte sedimentation rate, but systemic inflammatory response does not always show a positive correlation with inflammatory activity in the vessel wall. Therefore, imaging studies play a principal role in diagnosis and control of the disease. Glucocorticoids remain the most effective and serve as a cornerstone first line treatment. Immunosuppressive drugs play an important role as well, and biological therapy is increasingly being included in the treatment. This article describes the epidemiology, pathophysiology, diagnostics and treatment of this rare disease, so as to alert clinicians because disease left untreated can lead to narrowing and even closure of vital blood vessels. The most common Takayasu arteritis complications include pulmonary thrombosis, aortic regurgitation, congestive heart failure, cerebrovascular events, vision degeneration or blindness, and hearing problems.
\end{abstract}

Keywords: Autoimmune vasculitis; Inflammatory markers; Large vessel vasculitis; Takayasu arteritis

Abbreviations: ACR, the American College of Rheumatology; AECA, anti-epithelial cell antibodies; AZA, azathioprine; BVAS, the Birmingham Vasculitis Activity Score; CEUS, contrast-enhanced ultrasonography; CHCC, the Chapel Hill Consensus Conference; CRP, C-reactive protein; CT, computerized tomography; CYC, cyclophosphamide; ESR, erythrocyte sedimentation rate; FDG-PET/CT, Fludeoxyglucose positron emission tomography - computerized tomography; GC, glucocorticosteroids; GCA, Giant cell arteritis; HLA, Human leukocyte antigens; ITAS, the Indian Takayasu Clinical Activity Score; NKG2D, killer cell lectin-like receptor subfamily K; LEF, leflunomide; MHC, the Major Histocompatibility Complex; MICA, the Major Histocompatibility Class I Chain-Related A; MMF, mycophenolate mofetil; MMPs, matrix metalloproteinases; MR, magnetic resonance; MTX, methotrexate; NIH, National Institute of Health; NK cells, natural killer cells; PDGF, platelet-derived growth factor; PGA, patients global assessment; TAK, Takayasu arteritis; TCZ, Tocilizumab; TNF, tumor necrosis factor; VEGF, vascular endothelial growth factor

\section{Introduction}

Takayasu arteritis (TAK) is a rare autoimmune, idiopathic, and chronic granulomatous large vessel vasculitis mainly affecting the aorta and its large branches. It induces a variety of nonspecific inflammatory (systemic and local) and ischemic symptoms due to the formation of stenotic lesions and thrombi. The inflammatory process initially leads to thickening of the arterial wall which may result in stenosis, occlusion, dilatation, aneurysm formation or rupture of the involved arteries (Jolly and Curran, 2005). Symptoms of the disease can be very diverse depending on the location and degree of involvement of the inflamed vessels. Clinical manifestations include fatigue, weight loss, fever, faintness, headache, and differences in arterial pressure between bilateral upper or lower limbs. The most severe symptoms include pulmonary thrombosis, aortic regurgitation, congestive heart failure, cerebrovascular events, degeneration of vision or blindness, and hearing problems. In severe cases, it is very difficult to feel a pulse in patients, and for this reason TAK is called 'pulseless disease' (Terao et al., 2014).

Correct diagnostics, early recognition and appropriate therapy are very important for prevention of severe complications. Glucocorticoids and immunosuppressive drugs are primarily used for treatment, but biological drugs are playing an increasing role in therapy. It is critical to elucidate the pathophysiological mechanisms involved in TAK for further treatment development.

\footnotetext{
* Author for correspondence: Dominika Podgórska, Clinical Provincial Hospital No. 2, Department of Rheumatology, Rzeszów, Lwowska 60, 35-301 Rzeszów, Poland; e-mail: dominikaepodgorska@wp.pl http://doi.org/10.32725/jab.2018.005

Submitted: 2018-02-09 • Accepted: 2018-11-07 • Prepublished online: 2019-01-09

J Appl Biomed 17/1: 12-20 • EISSN 1214-0287 • ISSN 1214-021X

(C) 2018 The Authors. Published by University of South Bohemia in České Budějovice, Faculty of Health and Social Sciences.

This is an open access article under the CC BY-NC-ND license.
} 


\section{Materials and methods}

The primary aim of this review is to provide information concerning Takayasu arteritis that includes:

- Epidemiology - an analysis of the distribution of TAK in different populations.

- Pathogenesis of this disease - attempts to elucidate biological mechanisms leading to the diseased state.

- Diagnostic methods of TAK.

- Treatment procedures for this sever illness.

The methods included a literature review of full length research articles examining the issue of Takayasu arteritis. The main scientific database used to find the information on TAK was PubMed. The database was searched from 01.01.2000 to 30.12.2017 for the keywords: Takayasu arteritis (1112 results), Takayasu arteritis epidemiology (133), Takayasu arteritis pathogenesis (608), Takayasu arteritis diagnostic (842) and Takayasu arteritis treatment (638).

For those papers that fulfilled the criteria for quality, data were extracted according to the following content: date published, relevance of journal, and possible conflicts of interest. Non-English publications were excluded. We also performed a manual search within the references of the selected articles for any relevant articles that we might have missed or which went beyond the range of established dates.

According this criteria, more than 550 abstracts and 186 full text articles were found and from these 100 articles were included.

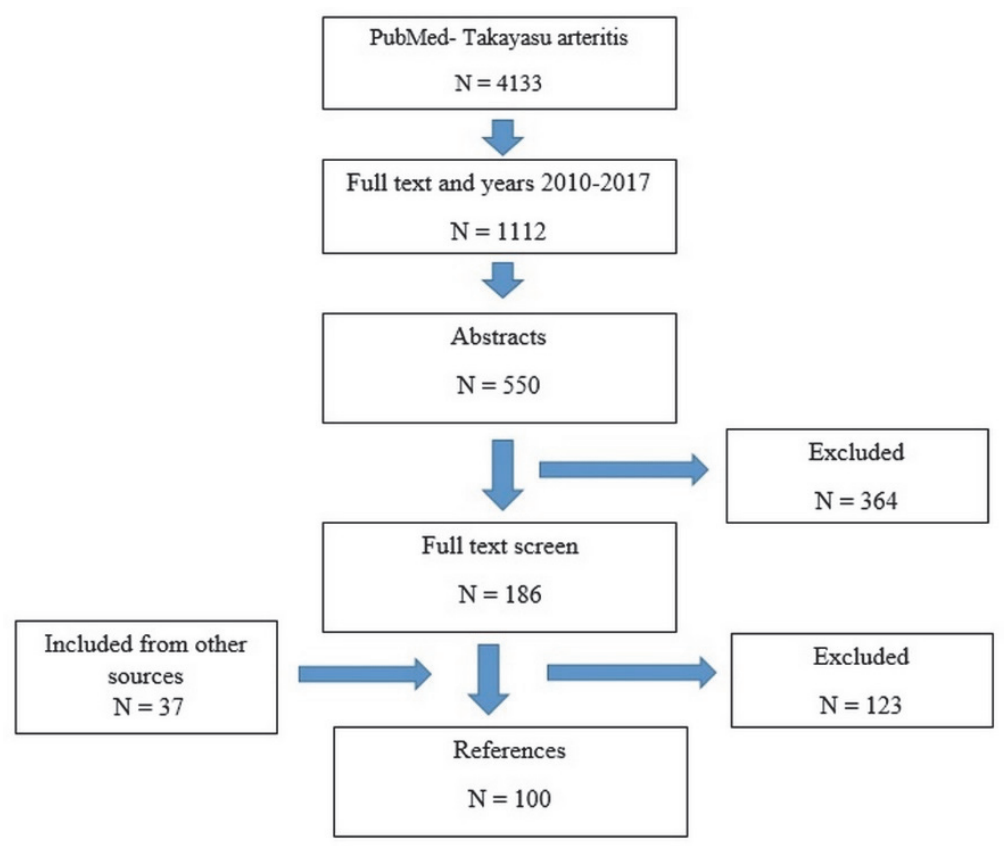

Fig 1. Flow diagram which summarizes the results of the selection procedure

\section{Results and discussion}

\section{Historical outline}

The disease is named after Mikito Takayasu, a professor of ophthalmology at Kanazawa University in Japan (Numano, 2002), who first reported a case of the disease in 1908 at the Annual Meeting of the Japan Ophthalmology Society. His patient was a 21 years old woman complaining of vision degeneration with observed anastomosis and aneurysmal changes of the retinal vessels (Terao, 2014). At this meeting, Katsutomo Onishi and Tsurukichi Kagoshima presented cases with similar ocular symptoms. Furthermore, they noticed that in their patients the pulse could not be palpated in both radial arteries (Onishi) or in the left radial artery (Kagoshima) (Numano, 1992). While Dr Takayasu is regarded to be the first to report a patient with TAK, there were other prior potential case reports of patients with TAK. A 40 years old woman suffering from pulseless disease was described in 1761 by Giovanni Battista Morgagni (Lazzarin et al., 2005), and a 45 years old man suffering from fever who developed pulseless disease in both carotid arteries was reported by Rokushu Yamamoto in 1830
(Numano, 2002). Also, Kentaro Shimizu and Keiji Sano introduced this disease in English literature as pulseless disease (Shimizu and Sano, 1951). They described the clinical features of pulseless, coronary anastomosis in retinal vasculature, and accentuated carotid sinus reflex as the characteristic triad of this morbid condition in 1948. However, in 1975, the research committee of the Department of Health and Welfare in Japan proposed the use of 'Takayasu arteritis' in memory of the first reporter, Mikito Takayasu (Numano, 2002).

\section{Epidemiology}

Takayasu arteritis is a rare disease, with an estimated incidence of 1-2 per million in Japan (Koide, 1992) and 2.2 per million in Kuwait (el-Reshaid et al., 1995). Patients with TAK are more frequently observed in Asian countries, but we can find them all over the world. Recent epidemiologic studies suggested that TAK is being increasingly recognized in Europe with a reported incidence rate between 0.4 to 1.5 per million (Dreyer et al., 2011; Gudbrandsson et al., 2017; Romero-Gómez et al., 2015; Watts et al., 2009). The highest prevalence of TAK has been described in Japan (40 cases/million) (Numano and Kobayashi, 1999) and the lowest one in United States (0.9 cases/million) 
(Cotch and Hoffmann, 1995). The prevalence of TAK in other countries ranges from 4.7 to 33.0 cases per million (Gudbrandsson et al., 2017; Romero-Gómez et al., 2015). This variation between studies may be derived from geographical and genetic differences between the populations and migration movements, but also may be due to methodological differences (Onen and Akkoc, 2017).

Takayasu arteritis is usually diagnosed in young individuals in their second and third decade of life and affects females in most cases (82.9-97.0\%) (de Souza and de Carvalho, 2014; Gudbrandsson et al., 2017; Richards et al., 2010). Generally, TAK has been defined arbitrarily as a disease with onset prior to the age of 40 . An age $<40$ years was selected as a mandatory criterion in the original Ishikawa diagnostic criteria and is a non-mandatory criterion in the 1990 American College of Rheumatology (ACR) classification criteria. However, occurrence of TAK in patients older than 40 years is not rare. Recent studies conducted in different populations indicate that the proportion of patients aged over 40 years at disease onset varies from 9 to 32\% (Arnaud et al., 2010; Gudbrandsson et al., 2017; Karageorgaki et al., 2009; Soto et al., 2008) and at the time of diagnosis varies from 15 to $71 \%$ (Dreyer et al., 2011; Mohammad and Mandl, 2015; Watts et al., 2009).

\section{Diagnosis}

Takayasu arteritis is a difficult disease to deal with. Early recognition is not easy and requires clinical awareness. Moreover, there are no reliable parameters reflecting disease activity (Direskeneli et al., 2011; Keser et al., 2014). To date, no established biological marker specific to the diagnosis of patients with TAK has been reported.

Patients with TAK often present increased inflammation markers, including $\mathrm{C}$-reactive protein (CRP) and erythrocyte sedimentation rate (ESR). However, systemic inflammatory response does not always show a positive correlation with inflammatory activity in the vessel wall. Therefore TAK may be active without increasing CRP or ESR, and vice versa. In patients with apparent clinical and laboratory remission, arterial specimens may show histological signs of vasculitis (Salvarani et al., 2003; Seyahi, 2017).

Imaging of arteries is very useful in diagnosing TAK and for patient follow-up. Conventional angiography was formerly the gold standard, and currently it is often replaced with computerized tomography (CT) or magnetic resonance (MR) angiography in routine practice (Alibaz-Oner and Direskeneli, 2015; Kato et al., 2015). Additionally, ultrasonography, especially contrast-enhanced ultrasonography (CEUS) of carotid arteries might be useful as a non-invasive method of detecting active vascular inflammation (Germanò et al., 2017). Fludeoxyglucose positron emission tomography computerized tomography (FDG-PET/CT) has emerged as a new diagnostic tool as it shows vascular inflammation even before any structural changes (Chrapko et al., 2016). A residual FDG uptake, despite clinical remission can be still observed during the follow-up (Seyahi, 2017).

Imaging methods allow to distinguish different types of TAK, depending on location of vascular lesions. The disease can be classified into 5 types:

Type I: classic pulseless type that affects blood vessels of aortic arch; involving the brachiocephalic trunk, carotid and subclavian arteries.

Type II: affects descending thoracic and abdominal aorta.

Type III: affects aortic arch and abdominal aorta.

Type IV: affects pulmonary artery and any of the above types.
Type V: with involvement of the coronary arteries and any of the above types (Gulati and Bagga, 2010).

Mavrogeni and colleagues suggested an imaging algorithm for Takayasu arteritis, as follows:

1. CT and MRI are of equal value for vessel luminography, but are less invasive than angiography.

2. Use MRI if possible rather than $\mathrm{CT}$ due to the lack of radiation.

3. Evaluate the heart; Echocardiography is sufficient for valvular and left ventricular function evaluation. However, if there is need for quantification of aortic regurgitation and myocarditis detection, MRI is superior.

4. Ultrasound is excellent for evaluating extracranial carotid arteries.

5. Use PET if the main complaint is fever of unknown origin.

6. The combination of PET-MRI is preferable to PET-CT and/ or PET alone.

7. Correlate imaging findings with clinical and laboratory findings (Mavrogeni et al., 2013).

There is no single imaging method that provides all the information required and each method has distinct and complementary roles in assessing disease activity and vascular inflammation. As a rule, the information obtained from non-invasive imaging methods should be integrated with patient symptoms, clinical findings and acute phase reactants to adjust the dose and the duration of treatment (Keser et al., 2014).

In cases when physicians suspected TAK, other disorders should be taken into consideration. Differential diagnosis includes infections (tuberculosis, syphilis, Staphylococcus aureus, Salmonella, Treponema, cytomegalovirus, herpes virus, hepatitis viruses and HIV), malignancies (e.g. leukemia, lymphoma, glioma, angiocentric lymphoma), immunodeficiency disorders, paraneoplastic syndrome, postradiation therapy, autoimmune secondary vasculitis (systemic lupus erythematosus, spondyloarthritis, sarcoidosis), kidney diseases and drugs (e.g. cocaine, sympathomimetics). In children, TAK should not be overlooked when we suspect inherited disorders (e.g. Marfan's syndrome, Ehlers Danlos' syndrome type IV, Loeys-Dietz's syndrome, neurofibromatosis type I, fibromuscular dysplasia, Grange syndrome), other autoimmune disorders primary vasculitis (Behçet's disease, Kawasaki's disease and thrombangiitis obliterans). In contrast, in adult patients TAK should not be overlooked in cases of atherosclerosis and arteriolosclerosis (hypercoagulable states - thrombotic thrombocytopenic purpura, antiphospholipid syndrome), vasospastic disorders (such as reversible cerebral vasoconstriction syndrome, reversible posterior leukoencephalopathy syndrome) (Brunner et al., 2010; Khasnis and Molloy, 2009).

\section{Diagnostic criteria}

For decades, clinical assessment of TAK was measured by the 'historic' National Institute of Health (NIH) criteria or so called Kerr criteria (Kerr et al., 1994) which are now realized to be insufficient. Thus, researchers were seeking a new assessment tool for recent clinical activity (Alibaz-Oner et al., 2015a; Aydin et al., 2015; Misra et al., 2013; Nakagomi and Jayne, 2016). The Indian Takayasu Clinical Activity Score (ITAS2010), based originally on the Birmingham Vasculitis Activity Score (BVAS), was developed and validated as the current composite index to assess disease activity in TAK (Misra et al., 2013). The Indian Takayasu Clinical Activity Score when compared with the Kerr criteria was found to be discriminatory during fol- 
low-up. On the other hand, agreement with patient global assessment was unsatisfactory (Alibaz-Oner et al., 2015a; Aydin et al., 2015). It is among 10 vasculitic disorders for which specific definitions were constructed at the International Chapel Hill Consensus Conference (CHCC) in 1994 and updated in 2012 (Jennette et al., 1994; 2013).

Due to similarities in histopathology, distribution of arterial lesions and female predominance between TAK and giant cell arteritis (GCA), it has been speculated that TAK and GCA could be a spectrum within the same disease (Grayson et al., 2012; Maksimowicz-McKinnon et al., 2009). Recently, however, the 2012 revised CHCC included both large vessel vasculitis as separate entities with differences in the age of disease onset. Takayasu arteritis was suggested to be a disease of predominantly younger individuals as compared to giant cell arteritis, a disease affecting people after an age of 50 years (Jennette et al., 2013). It should be emphasized that the descriptions made by the $\mathrm{CHCC}$ for specific vasculitic disorders were not intended to be used for classification or diagnosis, and therefore should not be used for such purposes (el-Reshaid et al., 1995).

The first criteria set for diagnosing TAK was developed by Ishikawa, and included one obligatory age criterion ( $<40$ years) and three major (two imaging and one clinical) and ten minor (two clinical, one laboratory and seven imaging) gauges (Ishikawa, 1988). This set of criteria was subsequently optimized by Sharma et al. (1996), who removed the obligatory criterion of age less than 40 years and revised some of the other criteria. Although both were published as diagnostic criteria, they were not formally validated for that purpose. The most frequently used diagnostic pattern in clinical and epidemiologic studies of TAK is ACR Classification Criteria, which includes five clinical and one imaging criteria (Arend et al., 1990).

A diagnosis of Takayasu arteritis according to the criteria of ACR from 1990, might be made if a patient has at least three of these six criteria present:

1. Age $<40$ years at disease onset.

2. Claudication of extremities.

3. Decreased brachial artery pulse.

4. Difference of $>10 \mathrm{mmHg}$ in systolic blood pressure between arms.

5. Bruit audible on auscultation over one or both subclavian arteries or abdominal aorta.

6. Pathological changes (usually focal or segmental) in aortic arteriography and/or its branches (Arend et al., 1990).

\section{Clinical features, signs and symptoms}

The diagnosis of TAK may be extremely challenging because non-specific systemic inflammatory symptoms are the only notable clinical findings in early phases of the disease, which follow a subtle and insidious clinical course until the emergence of vascular ischemic symptoms (Onen and Akkoc, 2017). Clinical features include fever, malaise, muscle aches, weight loss, faintness, fatigue. Patients with TAK also show the following symptoms depending on the location of vascular changes - arthralgia, carotidinia, limb claudication, arterial bruit, headache, neurological symptoms, differences in arterial pressure between bilateral upper or lower limbs. Inflammation lasting for a long time in branches of the aorta leads to narrowing and occlusion of these vessels. In advanced stages of the disease, it is very hard to detect a pulse in affected patients. In a severe course of TAK, pulmonary thrombosis, cerebral infarction, degeneration of vision or blindness, hearing problems, angina, myocardial infraction, heart failure, aortic valvular regurgi- tation and even sudden death can occur (Terao et al., 2014). Factors that contribute to significant morbidity in TAK include heart failure and neurological ischemic events such as stroke and transient ischemic attacks (Maksimowicz-McKinnon and Hoffman, 2007; Rav-Acha et al., 2007). Moreover, patients are at higher risk for cardiovascular disease than controls (de Carvalho et al., 2009; de Souza et al., 2009). Subclinical accelerated atherosclerosis is well documented in TAK, as a potential factor for ischemic complications (Seyahi et al., 2006). The leading cause of death in TAK patients is congestive heart failure (Jain et al., 1996; Park et al., 2005).

Although the life expectancy of patients with this disease was estimated to be low, introduction of glucocorticosteroids and immunosuppressant drugs has radically improved prognosis of treatment. This improvement may be attributed to a deeper understanding of this disease among physicians that has led to better patient management (Ishikawa and Maetani, 1994; Terao et al., 2014). A proper diagnosis of TAK is an important issue since delays may result in significant morbidity.

\section{Pathogenesis}

The etiopathogenesis of the arteritis is not known, but studies are being conducted regarding immunological and genetic aspects of this disease (Jain and Pondaiah, 2015). The pathogenesis of TAK remains unclear but it is characterized by the involvement of all arterial layers (i.e. panarteritis) with a variable inflammatory infiltrate including granulomatous inflammation, chronic or acute exudative inflammation, situated mainly in the media and adventitia while in the intimal layer, predominant hyperplasia and neovascularization are observed (Mason, 2010). Basic involvement of the aorta can be observed in adventitia media and inflammatory lesions can be found in the vasa vasorum (Hotchi, 1992). Thus, activation of vasa vasorum endothelial cells and recruitment of lymphocytes should be involved in the process of TAK (Terao et al., 2014). The vasa vasorum are considered a portal entry of inflammatory cells and the cellular infiltrate is comprised of CD4+ T cells, CD8+ T cells, $\gamma \delta \mathrm{T}$ cells, natural killer (NK) cells, macrophages, and neutrophils (Arnaud et al., 2011). TNF- $\alpha$ production occurs primarily in macrophages, T cells and NK cells. TNF- $\alpha$ is important in the formation of granuloma (Tripathy et al., 2006; Wallis and Ehlers, 2005).

Pathological findings based on aortic tissues samples showed that $\gamma \delta \mathrm{T}$ and NK cells are engaged with apoptosis of endothelial cells by production of perforin and killer cell lectin-like receptor subfamily K (NKG2D) (Weyand and Goronzy, 2003). The $\gamma \delta \mathrm{T}$ and NK cells expressing NKG2D receptors recognize MICA (the major histocompatibility class I chain-related A) on vascular smooth muscle cells and release perforin, leading to acute inflammation. Proinflammatory cytokines are also released from the natural killer and T-cells, inducing the production of matrix metalloproteinases (MMPs) and amplifying the inflammatory response. This leads to an increase in the major histocompatibility complex (MHC) antigen and recruitment more of mononuclear cells within the vascular wall. Histocompatibility complexes are activated through Toll-like receptors. Peripheral T-cells in patients with TAK were reported to be in active state with increased CD4/CD8 ratio, suggesting dominant role of Th cells (Sagar et al., 1992). Th1 lymphocytes, through the production of interferon- $\gamma$, direct the formation of giant cells through activation of macrophage release of vascular endothelial growth factor (VEGF). VEGF causes increases in neovascularisation and platelet-derived growth factor (PDGF). This ultimately results in smooth muscle migration 
and intimal proliferation. Th17 cells induced by the IL-23 microenvironment also contribute to vascular lesions through activation of infiltrating neutrophils (Arnaud et al., 2011).

B-cell contribution of TAK remains controversial. Anti-epithelial cell antibodies (AECA) and anti-aorta antibodies were reported to be found in patients with TAK (Park et al., 2006a). In spite of several reports of functional involvement of AECA, its effect is still controversial (Große et al., 2014; Wang et al., 2011). AECAs have been detected in a wide range of pathological conditions, including systemic vasculitis. There is much evidence that AECAs play pathogenic roles in vasculitis, in endothelial cell activation and induction of apoptosis. None of the identified target antigens of AECAs are specific for endothelial cells, and endothelial cell-specific target antigens of AECAs in systemic vasculitis remain to be identified (Legendre et al., 2017). There are also reports that TAK patients often have anti-phospholipid antibodies (Misra et al., 1994; Servettaz et al., 2008), especially anti-cardiolipin, anti-annexin $V$ and anti- $\beta 2$ glycoprotein-I antibodies (Tripathy et al., 2003; Wang et al., 2011). However, the positivity of these autoantibodies and the functional meaning remain unclear (Terao et al., 2014).

TAK patients sera have been shown to contain different antibodies, for example anti-endothelial cells and anti-human heat shock protein-60/65 autoantibodies (Kumar Chauhan et al., 2004). However, none of them was specific for TAK and a marker for early diagnosis was not identified. High levels of plasma pentraxin-3 (PTX-3) and anti-endothelial cell antibodies were observed in the serum of patients with active disease (Dagna et al., 2011; Wang et al., 2011). The cytokine profiles were also examined in the sera of patients with TAK. Große et al. (2014) and Park et al. (2006b) found elevated IL-16 and IL-18 levels with the latter correlating well with disease activity. In other studies cytokines associated with pro-inflammatory responses (such as IL-6, IL-8 and IL-18) were significantly increased in patients with TAK compared to healthy controls (Alibaz-Oner et al., 2015b).

The association of TAK with particular HLA alleles suggests that genetic factors are involved in the etiopathogenesis of TAK. These genetic factors, both within and outside the HLA region, were examined and it was concluded that HLA-B*52 is the only gene that shows an association with TAK beyond ethnicity (Terao, 2016). A recent large scale genetic association study that involved Turkish and North American-European patients has identified and confirmed two independent susceptibility loci within the HLA region HLA-B/MICA and HLA-DQB1/HLA-DRB1. This study revealed an association between TAK and HLA-B*52 also in North American-European patients (Saruhan-Direskeneli et al., 2013). Recent studies shown that TAK has been associated with various non-HLA susceptibility loci. Some of these genes are involved in regulation of immune response. New genetic susceptibility loci were found in IL6, IL12B, RPS9/LILRB3, FCGR2A/3A and a locus on chromosome 21 near PSMG1 (21q22) (Renauer and Sawalha, 2017; Renauer et al., 2015; Terao et al., 2013).

\section{Treatment}

Assessment of disease activity in Takayasu arteritis is very difficult. In many patients, despite the symptoms of active disease, serum levels of acute phase reactants are not increased, whereas it happens that the patient appears to be in remission of the disease, but there are other laboratory or radiological evidences of active inflammation (Seyahi, 2017).

We can distinguish 4 treatment steps, depending on the disease progression.
Step 1. Glucocorticoids remain the basic and the most effective first line TAK treatment. Initially, in the presence of active TAK disease, the treatment of choice is high-dose $(0.8-1 \mathrm{mg} /$ $\mathrm{kg} /$ day, p.o.) prednisolone or an equivalent. Generally, twothirds of the total daily dose is given early in the morning and the rest of the dose in the evening after meals. This treatment is maintained until symptoms and laboratory evidence (ESR, CRP) of inflammation normalize (usually 4-6 weeks, sometimes up 12 weeks). With control of inflammation, corticosteroid therapy can be tapered to (typically about 10 percent every week) a maintenance dose of $0.1-0.2 \mathrm{mg} / \mathrm{kg} /$ day $(\leq 15 \mathrm{mg} /$ day). For the prevention of relapse, treatment is usually continued for 1-2 years.

The response to high dose prednisolone is generally favorable, but relapses may occur while gradually tapering the dose and adverse effects of long-term treatment can cause problems. Therefore sometimes physicians start treatment from conventional immunosuppressant agents together with initial glucocorticosteroid treatment or while tapering the steroid dose (Aydin et al., 2015; Kötter et al., 2012; Sun et al., 2017).

Step 2. Immunosuppressive therapy should be implemented for patients who have a disease with high activity, if treatment is ineffective, and when the dose of steroids should be reduced due to side effects. A Helpful assessment of the activity of the disease can be a PGA or Kerr disease activity score. Clinical remission is defined as: Kerr score reduction to $\leq 1$ and glucocorticoid (GC) treatment at a dose of $\leq 0.2 \mathrm{mg} / \mathrm{kg} /$ day $(\leq 15 \mathrm{mg} /$ day).

Non-biological immunosuppressive agents include, among others, methotrexate (MTX), cyclophosphamide (CYC), azathioprine (AZA), mycophenolate mofetil (MMF) and leflunomide (LEF). CYC is usually used for the treatment of systemic vasculitis when the condition is severe or life threatening. CYC is applied via a single monthly dose of $0.5-0.75 \mathrm{~g} / \mathrm{m}^{2} \mathrm{i} . \mathrm{v}$ (usually $0.8 \mathrm{~g}$ ) and it is kept until remission is achieved and then shifted to MTX or AZA. CYC is the use of conventional immunosuppressive agents, unfortunately, has not shown consistent benefit in maintaining disease remission or reducing glucocorticoid-associated adverse events. MTX is given at an initial dose of 10-15 mg weekly p.o., and in the absence of side effects, it is tailored to a maximum dose of $25 \mathrm{mg} / \mathrm{w}$. If remission has been achieved, MTX 10-15 mg/w, p.o. or AZA 25$50 \mathrm{mg} /$ daily can be used as a maintenance dose. When Kerr score reduction to $<1$, steroids are required at a dose of $<0.2 \mathrm{mg} / \mathrm{kg} /$ day ( $<15 \mathrm{mg}$ daily). In the maintenance phase, MTX 10-15 mg/week p.o. or AZA $25-50 \mathrm{mg} /$ day p.o. LEF 10-20 mg/day p.o. are recommended. MMF remains a frequently used drug in the treatment process ( $2-3 \mathrm{~g} /$ day, majority $2 \mathrm{~g}$ /day). Immunosuppressive therapy is continued for at least 2 years after TAK remission. The effectiveness of available non-GC drugs for patients with TAK is limited: remission rates are approximately $60 \%$ and relapses occur in $>30 \%$ when they are given in combination with GC (Barra et al., 2018; de Souza et al., 2012; Goel et al., 2018; Koster et al., 2016).

In cases where immunosuppressive drugs are insufficient, biological therapy should be introduced.

Step 3. Biological drugs are increasingly used in therapy. Observational studies provide evidence that biological agents such as anti-tumor necrosis factor (anti-TNF), rituximab and tocilizumab are beneficial and could be used effectively in refractory TAK (Mekinian et al., 2015). Biological agents are not recommended as monotherapy (i.e. without GC) nor as firstline, add-on therapy to GC in newly-diagnosed TAK patients (Muratore et al., 2017). 


\section{Overview of the most important biological drugs used in treatment of Takayasu arteritis}

\section{Tocilizumab (TCZ)}

Interleukin 6 (IL-6) is thought to play an important role in the pathogenesis of TAK. There is an increase in the expression of IL-6 in vascular lesions among patients with TAK (Arnaud et al., 2011; Saadoun et al., 2015; Vaglio et al., 2013) and it is noted that elevated serum IL-6 correlates with disease activity (Park et al., 2006b). Therefore, anti-IL-6 therapy seems to be a reasonable option in patient management. Tocilizumab (TCZ), a humanized anti-IL-6 receptor inhibitory monoclonal antibody, could be an alternative for treating refractory Takayasu arteritis patients (Seyahi, 2017). Observational studies showed that, although TCZ leads to normalization of acute phase reactants and to remission, some patients have observed symptoms of silent vascular progression and radiographic deterioration occurred in the setting of normal acute phase reactants and despite treatment with TCZ (Bredemeier et al., 2012; Tombetti et al., 2013; Xenitidis et al., 2013). Because IL-6 blockade directly reduces hepatic production of C-reactive protein, inflammatory markers may not reliably present disease activity and ongoing vascular inflammation could be independent of IL-6 (Koster et al., 2016). Although TCZ appears effective in refractory TAK, information on its use in newly diagnosed patients to conventional immunosuppression or anti-TNF therapy is limited (Arita et al., 2015; Mekinian et al., 2015; Salvarani et al., 2012). It should be noted that TCZ is also the first FDA-approved therapy in treatment of GCA (a disease belongs to the group of large vessels vasculitis, very similar to TAK) (Stone et al., 2017).

\section{Ustekinumab}

Ustekinumab is a monoclonal antibody against IL-12/23. The interleukin-12-B gene region has recently been identified as a TAK susceptibility gene through a genome-wide association study (Terao et al., 2013), raising the likelihood that interleukin-12 is involved in the pathogenesis of TAK. Japanese researchers conducted a pilot clinical trial with ustekinumab in patients with refractory Takayasu arteritis and found favorable results (Terao et al., 2016). They noted that despite the good clinical response (treatments were well tolerated and inflammatory markers decreased), a reduction in vascular wall enhancement was not observed. Further clinical studies are therefore necessary to determine the future role of ustekinumab in TAK (Koster et al., 2016). There are also attempts to use ustekinumab in giant cell arteritis (Conway et al., 2016).

\section{TNF inhibitors}

Observational evidence supports the use of TNF inhibitors in TAK. In studies published by Clifford and Hoffman (2014), Mekinian et al. (2015) and Novikov et al. (2013) the efficacy of TNF inhibitors (infliximab, adalimumab, etanercept) in patients with refractory TAK was described. Most patients taking anti-TNF were able to reduce or discontinue glucocorticoids and relapse free survival was significantly longer than that observed with the non-biological immunosuppressive agents. Additionally, positron emission tomography scans showed reduction of vascular inflammation in most treated patients. Treatment maintained complete or partial remission. In summary, observational studies provide evidence that TNF-inhibitors are beneficial in refractory TAK. The benefit of early initiation in newly diagnosed patients is unknown and randomized controlled trials are needed to confirm the utility of these medications in TAK (Koster et al., 2016).

\section{Rituximab}

Although T-cell lymphocytes play an important role in pathogenesis, dysregulation of B-cell homeostasis may also play a role in this disease. Rituximab, a chimeric anti-CD20 monoclonal antibody, may be helpful in treatment (Hoyer et al., 2012). The initial favorable outcomes of B-cell depletion therapy in small numbers of patients support a possible role of B cells in large vessel vasculitis pathogenesis and further studies are needed before rituximab becomes widely used in these diseases (Koster et al., 2016).

Regardless of the biological therapy used to induce remission, unfortunately in a significant number of patients (30$40 \%)$, relapse occurs after discontinuation of treatment. This underlines the need for immunosuppression in patients with TAK and better understanding of the pathogenic mechanisms underlying these conditions. It should be noted that effective suppression of systemic inflammation and its associated symptoms does not necessarily equate to resolution of arterial wall inflammation, and detailed follow-up with arterial imaging is required, initially every 6 months to exclude progressive arterial disease (Tombetti and Mason, 2018).

Step 4. Surgery. In chronic stages of TAK, patients with ischemic symptoms need to be treated with endovascular revascularization or vascular surgery (such as balloon angioplasty or stent). Procedures should be undertaken only after the suppression of inflammation in the affected arteries. Surgical procedures carry risk of restenosis or occlusion and success rate depends upon the location and stage of stenosis of blood vessel (Keser et al., 2014).

\section{Conclusions}

Takayasu arteritis belongs to rare, idiopathic diseases of the immune system affecting the aorta and its branches. It is increasingly recognized in Europe and clinical practitioners should be aware of this disease. Non-specific systemic symptoms, which are accompanied by no pulse or various types of ischemic symptoms, should be considered along with deep diagnostic imaging. Early diagnosis and proper treatment can protect the patient from dangerous complications.

Diagnosis and monitoring disease activity in TAK may be accomplished by the integrated use of non-invasive imaging methods, patient symptoms, clinical findings and acute phase reactants. However, there is no single imaging method that provides all the information required and each method has distinct and complementary roles in assessing disease activity and vascular inflammation. Glucocorticoids and immunosuppressive drugs are mainly used for treatment of the disease, but biological drugs are increasingly used in therapy. More research is needed to better understand the pathomechanisms of this disease, as well as to introduce new drugs and treatment regimens so that disease remissions are longer, treatments more effective, leading to a better life quality for patients.

\section{Conflict of interests}

The authors have no conflict of interests to disclose.

\section{References}

Alibaz-Oner F, Direskeneli H (2015). Update on Takayasu's arteritis. Presse Med 44(6): e259-265. DOI: 10.1016/j.lpm.2015.01.015.

Alibaz-Oner F, Aydin SZ, Akar S, Aksu K, Kamali S, Yucel E, et al. (2015a). Assessment of Patients with Takayasu Arteritis in 
Routine Practice with Indian Takayasu Clinical Activity Score. J Rheumatol 42(8): 1443-1447. DOI: 10.3899/jrheum.140817.

Alibaz-Oner F, Yentür SP, Saruhan-Direskeneli G, Direskeneli H (2015b). Serum cytokine profiles in Takayasu's arteritis: search for biomarkers. Clin Exp Rheumatol 33(2): 32-35.

Arend WP, Michel BA, Bloch DA, Hunder GG, Calabrese LH, Edworthy SM, et al. (1990). The American College of Rheumatology 1990 criteria for the classification of Takayasu arteritis. Arthritis Rheum 33(8): 1129-1134. DOI: 10.1002/ art.1780330811.

Arita Y, Nakaoka Y, Otsuki M, Higuchi K, Hashimoto-Kataoka T, Yasui T, et al. (2015). Cytokine storm after cessation of tocilizumab in a patient with refractory Takayasu arteritis. Int J Cardiol 187: 319-321. DOI: 10.1016/j.ijcard.2015.03.399.

Arnaud L, Haroche J, Limal N, Toledano D, Gambotti L, Costedoat Chalumeau N., et al. (2010). Takayasu arteritis in France: a singlecenter retrospective study of 82 cases comparing white, North African, and black patients. Medicine (Baltimore) 89(1): 1-17. DOI: 10.1097/MD.0b013e3181cba0a3.

Arnaud L, Haroche J, Mathian A, Gorochov G, Amoura Z (2011). Pathogenesis of Takayasu's arteritis: a 2011 update. Autoimmun Rev 11(1): 61-67. DOI: 10.1016/j.autrev.2011.08.001.

Aydin SZ, Direskeneli H, Sreih A, Alibaz-Oner F, Gul A, Kamali S, et al. (2015). Update on Outcome Measure Development for Large Vessel Vasculitis: Report from OMERACT 12. J Rheumatol 42(12): 2465-2469. DOI: 10.3899/jrheum.141144.

Barra L, Yang G, Pagnoux C (2018). Non-glucocorticoid drugs for the treatment of Takayasu's arteritis: A systematic review and meta-analysis. Autoimmun Rev 17(7): 683-693. DOI: 10.1016/j. autrev.2018.01.019.

Bredemeier M, Rocha CM, Barbosa MV, Pitrez EH (2012). One-year clinical and radiological evolution of a patient with refractory Takayasu's arteritis under treatment with tocilizumab. Clin Exp Rheumatol 30(1): S98-100.

Brunner J, Feldman BM, Tyrrell PN, Kuemmerle-Deschner JB, Zimmerhackl LB, Gassner I, et al. (2010). Takayasu arteritis in children and adolescents. Rheumatology (Oxford) 49(10): 1806-1814. DOI: 10.1093/rheumatology/keq167.

Chrapko BE, Chrapko M, Nocuń A, Stefaniak B, Zubilewicz T, Drop A (2016). Role of 18F-FDG PET/CT in the diagnosis of inflammatory and infectious vascular disease. Nucl Med Rev Cent East Eur 19(1): 28-36. DOI: 10.5603/NMR.2016.0006.

Clifford A, Hoffman GS (2014). Recent advances in the medical management of Takayasu arteritis: an update on use of biologic therapies. Curr Opin Rheumatol 26(1): 7-15. DOI: 10.1097/ BOR.0000000000000004.

Conway R, O'Neill L, O’Flynn E, Gallagher P, McCarthy GM, Murphy CC, et al. (2016). Ustekinumab for the treatment of refractory giant cell arteritis. Ann Rheum Dis 75(8): 1578-1579. DOI: 10.1136/annrheumdis-2016-209351.

Cotch MF, Hoffmann GS (1995). The prevalence, epidemiology and cost of hospitalizations for vasculitis in New York State 1986 to 1990. Arthritis Rheumatol 38: 225.

Dagna L, Salvo F, Tiraboschi M, Bozzolo EP, Franchini S, Doglioni C, et al. (2011). Pentraxin-3 as a marker of disease activity in Takayasu arteritis. Ann Intern Med 155(7): 425-433. DOI: 10.7326/0003-4819-155-7-201110040-00005.

de Carvalho JF, Bonfá E, Bezerra MC, Pereira RM (2009). High frequency of lipoprotein risk levels for cardiovascular disease in Takayasu arteritis. Clin Rheumatol 28(7): 801-805. DOI: 10.1007/ s10067-009-1153-8.

de Souza AW, de Carvalho JF (2014). Diagnostic and classification criteria of Takayasu arteritis. J Autoimmun: 48-49: 79-83. DOI: 10.1016/j.jaut.2014.01.012.

de Souza AW, Ataíde Mariz H, Torres Reis Neto E, Diniz Arraes AE, da Silva NP, Sato EI (2009). Risk factors for cardiovascular disease and endothelin-1 levels in Takayasu arteritis patients. Clin Rheumatol 28(4): 379-383. DOI: 10.1007/s10067-008-1056-0.

de Souza AW, da Silva M, Machado SL, Oliveira AC, Pinheiro FA, Sato EI (2012). Short-term effect of leflunomide in patients with Takayasu arteritis: An observational study. Scand J Rheumatol 41(3): 227-230. DOI: 10.3109/03009742.2011.633553.
Direskeneli H, Aydin SZ, Merkel PA (2011). Assessment of disease activity and progression in Takayasu's arteritis. Clin Exp Rheumatol 29(1): S86-91.

Dreyer L, Faurschou M, Baslund B (2011). A population-based study of Takayasu's arteritis in eastern Denmark. Clin Exp Rheumatol 29: S40-42.

el-Reshaid K, Varro J, al-Duwairi Q, Anim JT (1995). Takayasu's arteritis in Kuwait. J Trop Med Hyg 98(5): 299-305.

Germanò G, Macchioni P, Possemato N, Boiardi L, Nicolini A, Casali M, et al. (2017). Contrast-Enhanced Ultrasound of the Carotid Artery in Patients With Large Vessel Vasculitis: Correlation With Positron Emission Tomography Findings. Arthritis Care Res (Hoboken) 69(1): 143-149. DOI: 10.1002/ acr.22906.

Goel R, Danda D, Joseph G, Ravindran R, Kumar S, Jayaseelan V, et al. (2018). Long-term outcome of 251 patients with Takayasu arteritis on combination immunosuppressant therapy: Single centre experience from a large tertiary care teaching hospital in Southern India. Semin Arthritis Rheum 47(5): 718-726. DOI: 10.1016/j.semarthrit.2017.09.014.

Grayson PC, Maksimowicz-McKinnon K, Clark TM, Tomasson G, Cuthbertson D, Carette S, et al. (2012). Distribution of arterial lesions in Takayasu's arteritis and giant cell arteritis. Ann Rheum Dis 71(8): 1329-1334. DOI: 10.1136/annrheumdis-2011-200795.

Große K, Witte T, Moosig F, Hoyer BF, Lansche C, Schmidt RE, Baerlecken NT (2014). Association of ferritin antibodies with Takayasu arteritis. Clin Rheumatol 33(10): 1523-1526. DOI: 10.1007/s10067-014-2764-2.

Gudbrandsson B, Molberg Ø, Garen T, Palm Ø (2017). Prevalence, Incidence, and Disease Characteristics of Takayasu Arteritis by Ethnic Background: Data From a Large, Population-Based Cohort Resident in Southern Norway. Arthritis Care Res (Hoboken) 69(2): 278-285. DOI: 10.1002/acr.22931.

Gulati A, Bagga A (2010). Large vessel vasculitis. Pediatr Nephrol 25(6): 1037-1048. DOI: 10.1007/s00467-009-1312-9.

Hotchi M (1992). Pathological studies on Takayasu arteritis. Heart Vessels Suppl 7(1): 11-17. DOI: 10.1007/BF01744538.

Hoyer BF, Mumtaz IM, Loddenkemper K, Bruns A, Sengler C, Hermann K-G, et al. (2012). Takayasu arteritis is characterised by disturbances of $\mathrm{B}$ cell homeostasis and responds to $\mathrm{B}$ cell depletion therapy with rituximab. Ann Rheum Dis 71(1): 75-79. DOI: 10.1136/ard.2011.153007.

Ishikawa K (1988). Diagnostic approach and proposed criteria for the clinical diagnosis of Takayasu's arteriopathy. J Am Coll Cardiol 12(4): 964-972. DOI: 10.1016/0735-1097(88)90462-7.

Ishikawa K, Maetani S (1994). Long-term outcome for 120 Japanese patients with Takayasu's disease. Clinical and statistical analyses of related prognostic factors. Circulation 90(4): 1855-1860. DOI: 10.1161/01.CIR.90.4.1855.

Jain S, Kumari S, Ganguly NK, Sharma BK (1996). Current status of Takayasu arteritis in India. Int J Cardiol 54: S111-116. DOI: 10.1016/S0167-5273(96)88780-8.

Jain S, Pondaiah SK (2015). Takayasu's arteritis: Review of epidemiology and etiopathogenesis. Indian J Rheumatol 10(1): S22-S29. DOI: 10.1016/j.injr.2015.07.009.

Jennette JC, Falk RJ, Andrassy K, Bacon PA, Churg J, Gross WL, et al. (1994). Nomenclature of systemic vasculitides. Proposal of an international consensus conference. Arthritis Rheum. 37(2): 187-192. DOI: 10.1002/art.1780370206.

Jennette JC, Falk RJ, Bacon PA, Basu N, Cid MC, Ferrario F, et al. (2013). 2012 revised International Chapel Hill Consensus Conference Nomenclature of Vasculitides. Arthritis Rheum 65(1): 1-11. DOI: 10.1002/art.37715.

Jolly M, Curran JJ (2005). Infliximab-responsive uveitis and vasculitis in a patient with Takayasu arteritis. J Clin Rheumatol 11(4): 213-215. DOI: 10.1097/01.rhu.0000173218.28013.3e.

Karageorgaki ZT, Bertsias GK, Mavragani CP, Kritikos HD, Spyropoulou-Vlachou M, Drosos AA, et al. (2009). Takayasu arteritis: epidemiological, clinical, and immunogenetic features in Greece. Clin Exp Rheumatol 27(1): S33-39.

Kato Y, Terashima M, Ohigashi H, Tezuka D, Ashikaga T, Hirao K, Isobe M (2015). Vessel Wall Inflammation of Takayasu Arteritis 
Detected by Contrast-Enhanced Magnetic Resonance Imaging: Association with Disease Distribution and Activity. Plos One 10(12): e0145855. DOI: 10.1371/journal.pone.0145855.

Kerr GS, Hallahan CW, Giordano J, Leavitt RY, Fauci AS, Rottem M, Hoffman GS (1994). Takayasu arteritis. Ann Intern Med 120(11): 919-929. DOI: 10.7326/0003-4819-120-11-199406010-00004.

Keser G, Direskeneli H, Aksu K (2014). Management of Takayasu arteritis: a systematic review. Rheumatology (Oxford) 53(5): 793-801. DOI: 10.1093/rheumatology/ket320.

Khasnis A, Molloy E (2009). Mimics of primary systemic vasculitides. Int J Clin Rheumatol 4(5): 597-609. DOI: 10.2217/ijr.09.37.

Koide K (1992). Takayasu arteritis in Japan. Heart Vessels Suppl 7: 48-54. DOI: 10.1007/BF01744544.

Koster MJ, Matteson EL, Warrington KJ (2016). Recent advances in the clinical management of giant cell arteritis and Takayasu arteritis. Curr Opin Rheumatol 28(3): 211-217. DOI: 10.1097/ BOR.0000000000000265.

Kötter I, Henes JC, Wagner AD, Loock J, Gross WL (2012). Does glucocorticosteroid-resistant large-vessel vasculitis (giant cell arteritis and Takayasu arteritis) exist and how can remission be achieved? A critical review of the literature. Clin Exp Rheumatol 30(1): S114-129.

Kumar Chauhan S, Kumar Tripathy N, Sinha N, Singh M, Nityanand S (2004). Cellular and humoral immune responses to mycobacterial heat shock protein-65 and its human homologue in Takayasu's arteritis. Clin Exp Immunol 138(3): 547-553. DOI: 10.1111/j.1365-2249.2004.02644.x.

Lazzarin P, Pasero G, Marson P, Cecchetto A, Zanchin G (2005) Takayasu's arteritis. A concise review and some observations on a putative case reported by Giovanni Battista Morgagni (1761). Reumatismo 57(4): 305-313. DOI: 10.4081/ reumatismo.2005.305.

Legendre P, Régent A, Thiebault M, Mouthon L (2017). Antiendothelial cell antibodies in vasculitis: A systematic review. Autoimmun Rev 16(2): 146-153. DOI: 10.1016/j. autrev.2016.12.012

Maksimowicz-McKinnon K, Clark TM, Hoffman GS (2009). Takayasu arteritis and giant cell arteritis: a spectrum within the same disease? Medicine (Baltimore). 88(4): 221-226. DOI: 10.1097/ MD.0b013e3181af70c1.

Maksimowicz-McKinnon K, Hoffman GS (2007). Takayasu arteritis: what is the long-term prognosis? Rheum Dis Clin North Am 33(4): 777-786. DOI: $10.1016 /$ j.rdc.2007.07.014.

Mason JC (2010). Takayasu arteritis-advances in diagnosis and management. Nat Rev Rheumatol 6(7): 406-415. DOI: 10.1038/ nrrheum.2010.82.

Mavrogeni S, Dimitroulas T, Chatziioannou SN, Kitas G (2013). The Role of Multimodality Imaging in the Evaluation of Takayasu Arteritis. Semin Arthritis Rheum 42(4): 401-412. DOI: 10.1016/j. semarthrit.2012.07.005.

Mekinian A, Comarmond C, Resche-Rigon M, Mirault T, Kahn JE, Lambert M, et al. (2015). Efficacy of Biological-Targeted Treatments in Takayasu Arteritis: Multicenter, Retrospective Study of 49 Patients. Circulation 132(18): 1693-1700. DOI: 10.1161/CIRCULATIONAHA.114.014321.

Misra R, Aggarwal A, Chag M, Sinha N, Shrivastava S (1994). Raised anticardiolipin antibodies in Takayasu's arteritis. Lancet 343(8913): 1644-1645. DOI: 10.1016/S0140-6736(94)93103-8.

Misra R, Danda D, Rajappa SM, Ghosh A, Gupta R, Mahendranath KM, et al. (2013). Development and initial validation of the Indian Takayasu Clinical Activity Score (ITAS2010). Rheumatology (Oxford) 52(10): 1795-1801. DOI: $10.1093 /$ rheumatology/ket128.

Mohammad AJ, Mandl T (2015). Takayasu arteritis in southern Sweden. J Rheumatol 42(5): 853-858. DOI: 10.3899/ jrheum.140843.

Muratore F, Pipitone N, Salvarani C (2017). Standard and biological treatment in large vessel vasculitis: guidelines and current approaches. Expert Rev Clin Immunol 13(4): 345-360. DOI: 10.1080/1744666X.2017.1285699.

Nakagomi D, Jayne D (2016). Outcome assessment in Takayasu arteritis. Rheumatology (Oxford) 55(7): 1159-1171. DOI: $10.1093 /$ rheumatology/kev366.
Novikov PI, Smitienko IO, Moiseev SV (2013). Tumor necrosis factor alpha inhibitors in patients with Takayasu's arteritis refractory to standard immunosuppressive treatment: cases series and review of the literature. Clin Rheumatol 32(12): 1827-1832. DOI: $10.1007 / \mathrm{s} 10067-013-2380-6$.

Numano F (1992). Introductory remarks for this special issue on Takayasu arteritis. Heart Vessels Suppl 7(1): 3-5.

Numano F (2002). The story of Takayasu arteritis. Rheumatology (Oxford) 41(1): 103-106.

Numano F, Kobayashi Y (1999). Takayasu arteritis - beyond pulselessness. Intern. Med. 38, 226-232.

Onen F, Akkoc N (2017). Epidemiology of Takayasu arteritis. Presse Med 46(7-8): e197-e203. DOI: 10.1016/j.lpm.2017.05.034.

Park MC, Lee SW, Park YB, Chung NS, Lee S-K (2005). Clinical characteristics and outcomes of Takayasu's arteritis: analysis of 108 patients using standardized criteria for diagnosis, activity assessment, and angiographic classification. Scand J Rheumatol 34(4): 284-292. DOI: 10.1080/03009740510026526.

Park MC, Lee SW, Park YB, Lee SK (2006b). Serum cytokine profiles and their correlations with disease activity in Takayasu's arteritis. Rheumatology (Oxford) 45(5): 545-548. DOI: 10.1093/ rheumatology/kei266.

Park MC, Park YB, Jung SY, Lee KH, Lee SK (2006a). Anti-endothelial cell antibodies and antiphospholipid antibodies in Takayasu's arteritis: correlations of their titers and isotype distributions with disease activity. Clin Exp Rheumatol 24(2): S10-16.

Rav-Acha M, Plot L, Peled N, Amital H (2007). Coronary involvement in Takayasu's arteritis. Autoimmun Rev 6(8): 566-571. DOI: 10.1016/j.autrev.2007.04.001.

Renauer P, Sawalha AH (2017). The genetics of Takayasu arteritis. Press Med 46(7-8): e179-e187. DOI: 10.1016/j.lpm.2016.11. 031.

Renauer PA, Saruhan-Direskeneli G, Coit P, Adler A, Aksu K, Keser G, et al. (2015). Identification of Susceptibility Loci in IL6, RPS9/ LILRB3, and an Intergenic Locus on Chromosome 21q22 in Takayasu Arteritis in a Genome-Wide Association Study. Arthritis Rheumatol 67(5): 1361-1368. DOI: 10.1002/art.39035.

Richards BL, March L, Gabriel SE (2010). Epidemiology of largevessel vasculidities. Best Pract Res Clin Rheumatol 24(6): 871-883. DOI: 10.1016/j.berh.2010.10.008.

Romero-Gómez C, Aguilar-García JA, García-de-Lucas MD, CotosCanca R, Olalla-Sierra J, García-Alegría JJ, Hernández-Rodríguez J (2015). Epidemiological study of primary systemic vasculitides among adults in southern Spain and review of the main epidemiological studies. Clin. Exp. Rheumatol. 33(2): S11-18.

Saadoun D, Garrido M, Comarmond C, Desbois AC, Domont F, Savey L, et al. (2015). Th1 and Th17 cytokines drive inflammation in Takayasu arteritis. Arthritis Rheumatol 67(5): 1353-1360. DOI: 10.1002/art.39037.

Sagar S, Ganguly NK, Koicha M, Sharma BK (1992). Immunopathogenesis of Takayasu arteritis. Heart Vessels Suppl 7: 85-90. DOI: 10.1007/BF01744550.

Salvarani C, Cantini F, Boiardi L, Hunder GG (2003). Laboratory investigations useful in giant cell arteritis and Takayasu's arteritis. Clin Exp Rheumatol 21(6): S23-28.

Salvarani C, Magnani L, Catanoso M, Pipitone N, Versari A, Dardani L, et al. (2012). Tocilizumab: a novel therapy for patients with large-vessel vasculitis. Rheumatology (Oxford) 51(1): 151-156. DOI: 10.1093/rheumatology/ker296.

Saruhan-Direskeneli G, Hughes T, Aksu K, Keser G, Coit P, Aydin SZ, et al. (2013). Identification of multiple genetic susceptibility loci in Takayasu arteritis. Am J Hum Genet 93(2): 298-305. DOI: 10.1016/j.ajhg.2013.05.026.

Servettaz A, Guilpain P, Camoin L, Mayeux P, Broussard C, Tamby MC, et al. (2008). Identification of target antigens of antiendothelial cell antibodies in healthy individuals: A proteomic approach. Proteomics 8(5) 1000-1008. DOI: 10.1002/ pmic.200700794.

Seyahi E (2017). Takayasu arteritis: an update. Curr Opin Rheumatol 29(1): 51-56. DOI: 10.1097/BOR.0000000000000343.

Seyahi E, Ugurlu S, Cumali R, Balci H, Seyahi N, Yurdakul S, Yazici H (2006). Atherosclerosis in Takayasu arteritis. Ann Rheum Dis 65(9): 1202-1207. DOI: 10.1136/ard.2005.047498. 
Sharma BK, Jain S, Suri S, Numano F (1996). Diagnostic criteria for Takayasu arteritis. Int J Cardiol 54: S141-147. DOI: 10.1016/ S0167-5273(96)88783-3.

Shimizu K, Sano K (1951). Pulseless disease. J Neuropathol Clin Neurol 1(1): 37-47.

Soto ME, Espinola N, Flores-Suarez LF, Reyes PA (2008). Takayasu arteritis: clinical features in 110 Mexican Mestizo patients and cardiovascular impact on survival and prognosis. Clin Exp Rheumatol 26(3): S9-15.

Stone JH, Tuckwell K, Dimonaco S, Klearman M, Aringer M, Blockmans D, et al. (2017). Trial of Tocilizumab in GiantCell Arteritis. N Engl J Med 377: 317-328. DOI: 10.1056/ NEJMoa1613849.

Sun Y, Ma L, Ma L, Kong X, Chen H, Lv P, et al. (2017). Cyclophosphamide could be a better choice than methotrexate as induction treatment for patients with more severe Takayasu's arteritis. Rheumatol Int 37(12): 2019-2026. DOI: 10.1007/ s00296-017-3847-6.

Terao C (2014). History of Takayasu arteritis and Dr. Mikito Takayasu. Int J Rheum Dis 17(8): 931-935. DOI: 10.1111/1756185X.12576.

Terao C (2016). Revisited HLA and non-HLA genetics of Takayasu arteritis - where are we? J Hum Genet 61(1): 27-32. DOI: $10.1038 /$ jhg.2015.87.

Terao C, Yoshifuji H, Kimura A, Matsumura T, Ohmura K, Takahashi M, et al. (2013). Two susceptibility loci to Takayasu arteritis reveal a synergistic role of the IL12B and HLA-B regions in a Japanese population. Am J Hum Genet 93(2): 289-297. DOI: 10.1016/j.ajhg.2013.05.024.

Terao C, Yoshifuji H, Mimori T (2014). Recent advances in Takayasu arteritis. Int J Rheum Dis 17(3): 238-247. DOI: 10.1111/1756185X.12309.

Terao C, Yoshifuji H, Nakajima T, Yukawa N, Matsuda F, Mimori T (2016). Ustekinumab as a therapeutic option for Takayasu arteritis: from genetic findings to clinical application. Scand J Rheumatol 45(1): 80-82. DOI: 10.3109/03009742.2015.1060521.
Tombetti E, Franchini S, Papa M, Sabbadini MG, Baldissera E (2013). Treatment of refractory Takayasu arteritis with tocilizumab: 7 Italian patients from a single referral center. J Rheumatol 40(12): 2047-2051. DOI: 10.3899/jrheum.130536.

Tombetti E, Mason JC (2018). Takayasu arteritis: advanced understanding is leading to new horizons. Rheumatology (Oxford) 4. DOI: 10.1093/rheumatology/key040.

Tripathy NK, Gupta PC, Nityanand S (2006). High TNF-alpha and low IL-2 producing T cells characterize active disease in Takayasu's arteritis. Clin Immunol 118(2-3): 154-158. DOI: 10.1016/j. clim.2005.09.010.

Tripathy NK, Sinha N, Nityanand S (2003). Anti-annexin V antibodies in Takayasu's arteritis: prevalence and relationship with disease activity. Clin Exp Immunol 134(2): 360-364. DOI: 10.1046/j.1365-2249.2003.02282.x.

Vaglio A, Catanoso MG, Spaggiari L, Magnani L, Pipitone N, Macchioni P, et al. (2013). Interleukin-6 as an inflammatory mediator and target of therapy in chronic periaortitis. Arthritis Rheum 65(9): 2469-2475. DOI: 10.1002/art.38032.

Wallis RS, Ehlers S (2005). Tumor necrosis factor and granuloma biology: explaining the differential infection risk of etanercept and infliximab. Semin Arthritis Rheum 34(5): 34-38. DOI: 10.1016/j. semarthrit.2005.01.009.

Wang H, Ma J, Wu Q, Luo X, Chen Z, Kou L (2011). Circulating B lymphocytes producing autoantibodies to endothelial cells play a role in the pathogenesis of Takayasu arteritis. J Vasc Surg 53(1): 174-180. DOI: 10.1016/j.jvs.2010.06.173.

Watts R, Al-Taiar A, Mooney J, Scott D, Macgregor A (2009). The epidemiology of Takayasu arteritis in the UK. Rheumatology (Oxford) 48(8): 1008-1011. DOI: 10.1093/rheumatology/kep153.

Weyand CM, Goronzy JJ (2003). Medium- and large-vessel vasculitis. N Engl J Med 349: 160-169. DOI: 10.1056/NEJMra022694.

Xenitidis T, Horger M, Zeh G, Kanz L, Henes JC (2013). Sustained inflammation of the aortic wall despite tocilizumab treatment in two cases of Takayasu arteritis. Rheumatology (Oxford) 52(9): 1729-1731. DOI: 10.1093/rheumatology/ket107. 